\title{
Growth, Leaf Gas Exchange and Secondary Metabolites of Orthosiphon stamineus as Affected by Multiwall Carbon Nanotubes Application
}

\author{
Ayu Izera Izad ${ }^{1}$, Mohd Hafiz Ibrahim ${ }^{1 *}$, Che Azurahanim Che Abdullah ${ }^{1}$ \\ and Nurul Amalina Mohd Zain ${ }^{2}$ \\ ${ }^{1}$ Faculty of Science, Universiti Putra Malaysia, 43400 Serdang, Selangor, Malaysia. \\ ${ }^{2}$ Faculty of Science, Institute of Biological Science, University of Malaya, 50603, Kuala Lumpur, \\ Malaysia.
}

\section{Authors' contributions}

This work was carried out in collaboration between all authors. Authors MHI and All designed the study, performed the statistical analysis, wrote the protocol and wrote the first draft of the manuscript.

Authors CACA and NAMZ managed the analyses of the study. Author All managed the literature searches. All authors read and approved the final manuscript.
Article Information
DOI: $10.9734 / A R R B / 2018 / 38113$
Editor(s):
(1) George Perry, Dean and Professor of Biology, University of Texas at San Antonio, USA.
Reviewers:
(1) Emel Yigit, Inonu Üniversity, Türkiye. (2) Md Zohurul Kadir Roni, Ehime University, Japan.
(3) Madhuri Sharon, Solapur University, India. Complete Peer review History: http://www.sciencedomain.org/review-history/23109

Original Research Article

Received $12^{\text {th }}$ October 2017 Accepted $28^{\text {th }}$ December 2017 Published $9^{\text {th }}$ February 2018

\section{ABSTRACT}

Aims: This study was conducted to study the growth, leaf gas exchange and secondary metabolites of Orthosiphon stamineus as affected by Multiwalled carbon nanotubes application (MWCNT).

Study Design: Orthosiphon stamineus were exposed to four different multi-walled carbon nanotubes (MWCNTs) concentration $\left(0,700,1400\right.$ and $2100 \mathrm{mg} \mathrm{L}^{-1}$ ). The experiment was organized in a randomized complete block (RCBD) design with three replications. Each experimental unit consisted of twelve plants, and there were a total of 144 plants used in the experiment.

Place and Duration of Study: Department of Biology, Faculty of Science Universiti Putra Malaysia between November 2016 to March 2017. 
Methodology: Each plant was watered with $50 \mathrm{~mL}$ of MWCNTs solution in week 2 and 9 . The leaves number were counted manually and the total plant biomass was taken by calculating the dry weight of root, stem, and leaf per seedling The total chlorophyll content in the leaves was measured using a SPAD chlorophyll meter. The leaf gas exchange was determined using LI6400XT portable photosynthesis system. Total phenolics and flavonoid were determined using Folin-Ciocalteu reagent.

Results: It was found that application of MWCNTs would reduce the growth characteristics of this plant that was shown by decreased leaf numbers, total biomass and total chlorophyll content (TCC). As MWCNTs concentration increases from $0>2100 \mathrm{mg} \mathrm{L}^{-1}$, the leaf gas exchange parameter also shows reduced patterns. Generally, as the rate of MWCNTs increased from $700>$ $2100 \mathrm{mg} \mathrm{L}^{-1}$ MWCNTs reduce the net photosynthesis $(\mathrm{A})$, stomatal conductance $\left(\mathrm{g}_{\mathrm{s}}\right)$, transpiration rate $(E)$ and increased the plant water use efficiency. The production of the secondary metabolites was directly dependable on MWCNTs concentration. As the rate was enhanced from $0>700>$ $1400>2100 \mathrm{mg} \mathrm{L}^{-1}$ the production of total phenolics and flavonoids was enhanced.

Conclusion: The current study revealed that the high application of MWCNTs concentration reduce the growth rate of $O$. stamineus, leaf gas exchange and simultaneously increase the production of secondary metabolites.

Keywords: Multi-walled carbon nanotubes (MWCNTs); Orthosiphon stamineus; growth; leaf gas exchange; secondary metabolites.

\section{INTRODUCTION}

Orthosiphon stamineus Benth. is a perennial herb that belongs to Lamiaceae family (Ameer [1]. This herb species is widely dispersed in temperate countries such as Malaysia, India, China and Australia which have a tropical climate with high temperature and rainfall all year [2]. In Southeast Asia, O. stamineus is a popular medicinal herb and it has been planted as an ornamental plant as well as for medicinal purposes [3]. Orthosiphon stamineus is used to treat jaundice, epilepsy, gallstones, influenza, and hepatitis and have a great potential in the herbal medicinal industry because of its antifungal, diuretic, and bacteriostatic properties of leaves [4]. Antioxidant activity in the leaves and its lipophilic flavonoids can prohibit the oxidative inactivation of 15-lipoxygenase [5].

Carbon nanotubes (CNT) is a tubular folded graphene having carbon hexagonal units. CNTs have few special electrical, mechanical and thermal properties. Currently, there are two groups of CNTs, i.e. single-walled carbon nanotubes (SWCNTs) and multiwalled carbon nanotubes (MWCNTs) [6]. The difference between both structures is that the amount of graphene sheet that wrapped around the tube core. A single graphene sheet was needed to form SWCNTs while several graphene sheets was needed to wrapped around the tube core to form MWCNTs [7]. Plants have the possibility to absorb certain concentration of the essential and non-essential elements in specific which may cause a toxicity to the plants [8]. Rico et al. [9] have concluded that the range of concentration of $1000-4000 \mathrm{mg} / \mathrm{L}$ is where the nanoparticles (carbon nanotubes and fullerenes) possess obvious toxicity on the food crops. The common high concentration of the nanoparticles which ranging between $2000-5000 \mathrm{mg} / \mathrm{L}$ is normally used to study the toxicity effect on the food crops $\left(\mathrm{C}_{3}\right.$ and $\mathrm{C}_{4}$ species) [10]. The toxic level of carbon nanotubes depends on the hydrophobic nature of nanotubes, existence of catalyst and surfactants [11]. The phytotoxic effects of CNTs on plant cells is caused by the aggregation and cell death which depends on its concentration [7]. Usually, the toxicity effects is shown by plant cell electrolyte leakage (increase in plant cell membrane permeability) and the swelling of the plant cells [11]. There is few research that demonstrates the inhibitory effect of MWCNTs on plants growth. Parvin and Brunshi [12] showed that the height and fresh weight of roots and shoots of red spinach as well as leaf number and leaf area were reduced with increasing MWCNTs doses over control. Tobacco cells that were cultured with MWCNTs contain genes that induce the growth by maintaining the cell division, the formation of the cell wall and the water flow through the membrane [13]. According to Moore [14], nanomaterials produce harmful reactive oxygen species (ROS), which elevates the cellular oxidative stress and may damage the DNA, proteins and membranes.

The application of carbon nanotubes also can enhance the leaf gas exchanges properties of 
the plant. It was observed in Arabidopsis thaliana that treated with single wall carbon nanotubes (SWCNT) the plant had higher photosynthetic, photoabsorption and higher electron transport rates [15] compared to the plant that not treated with the materials. This was due to a higher efficiency of chloroplast when interacted with the nanomaterials. Recently, [16] in their study on the plant nanobionics, have proved that CNTs penetration in chloroplasts and accumulation on the thylakoids and stroma can enhance the photochemical process in spinach. This was due to higher rates of electron transport and increment in photosynthesis efficiency of the plant treated with CNT. However different study showed a reduction in leaf gas exchange performance due to decreased of superoxide dismutase (SOD) activity as well as a decay of chlorophyll production in the treated plant [17].

Secondary metabolites, also known as natural products presence in low quantities and the production are widespread or restricted to certain families, genera or even species. They lack of biological significance but they have significant economic and medicinal value. Secondary metabolites protect plants from pathogens and insects, forming important UV-radiation absorbing compounds, which avoid any serious damage of the leaf [18] The condition of the surroundings such as light intensity, carbon dioxide levels, temperature, fertilization, and biotic and abiotic factors could affect the concentration of polyphenols [19]. Plant cell culture that was exposed to different types of elicitors (biotic and abiotic) can stimulate the biosynthesis of secondary metabolites. Ghorbanpour and Hadian [20] showed the first proof that the optimum use of MWCNTs can act as an elicitor to enhance the biosynthesis of phenolics and flavonoids in callus culture of Satureja khuzestanica due to the activation of specific key enzymes. Besides, they showed that the $S$. khuzestanica produce minimum phenolics content in medium containing the highest concentration of MWCNTs $\left(500 \mu \mathrm{g} \mathrm{ml}^{-1}\right)$.

The findings of the special effects of nanomaterials on the plant cause a significant growing industry with multiple applications of nanomaterials in biotechnology, agriculture, medicine and public health. Carbon nanotubes (CNTs) is the most studied carbon-based nanomaterials with high nano-technological demands [21]. Many effects of CNTs on plants and crops have been described for the application in agriculture but many other plants interaction mechanisms with the nanoparticles have not been fully studied [22]. At present, little work has been carried out to observe the effects of the application of CNT to medicinal plant especially, MWCNT. Indeed, at present, general research in the leaf gas exchange and secondary metabolites is still in its infancy. Therefore, a substantial study on the growth, leaf gas exchange and secondary metabolites of $O$. staminues is essential in order to understand the mechanism of plant and carbon nanotubes interaction. With this, the main objective of the research was to investigate the growth, leaf gas exchange and secondary metabolites patterns of $O$. stamineus as affected by Multiwall CNTs application (MWCNT). Secondly, to identify the best concentration for optimum growth and secondary metabolites of $\mathrm{O}$. stamineus under application of MWCNT and last objective was to establish the relationship between growth and secondary metabolites of $O$. stamineus as affected by MWCNTs application.

\section{MATERIALS AND METHODS}

\subsection{Properties and Synthesis of CNTs}

The CNT used in the study was multiwall carbon nanotubes (MWCNT). The range of the diameter of MWCNTs is about $23.6 \mathrm{~nm}$ to $28.1 \mathrm{~nm}$ with the purity of $80.01 \%$. The MWCNTs were synthesized from oil palm by using thermal vapor deposition method [23]. The ferrocene (catalyst) was directly dissolved in the oil palm at a concentration of $5.33 \%$ of weight to obtain a light brown solution. Six millimeters precursor mixture was introduced in the middle of precursor furnace by an alumina boat while silicon substrate was placed in the middle of the deposition furnace. The mixture was then vaporized at $450^{\circ} \mathrm{C}$ and pyrolyzed at $750^{\circ} \mathrm{C}$ for 30 - 90 minutes synthesis time with 10 minutes increment in argon ambient.

\subsection{Plant Material and Maintenance}

The experiment was conducted at the Taman Pertanian Universiti, Universiti Putra Malaysia. Stem cuttings were used as the source of planting materials in the study. Stem cuttings of O.stamineus were propagated for two weeks in a tray and then transferred to polybags filled with a mixture of top soil and sand (ratio 3:1). All the cuttings were irrigated four times a day or when necessary. After 1 months after propagation with stem cuttings, $O$. stamineus plants were exposed to four different multi-walled carbon nanotubes 
(MWCNTs) concentration (0, 700, 1400 and $2100 \mathrm{mg} \mathrm{L}^{-1}$ ). The MWCNTs were delivered to the plants through watering. The MWCNTs were dispersed in distilled water before being applied to the plants. Each plant was watered with 100 $\mathrm{mL}$ of MWCNTs solution. The experiment was organized in a randomized complete block (RCBD) design with three replications. Each experimental unit consisted of twelve plants, and there were a total of 144 plants used in the experiment.

\subsection{Leaf Numbers}

The whole leaves of the plants were counted manually (one by one piece) and then recorded.

\subsection{Plant Biomass}

Total plant biomass was taken by calculating the dry weight of root, stem and leaf per seedling. Plant parts were separated and placed in paper bags and oven dried at $80^{\circ} \mathrm{C}$ until constant weight was reached before dry weights were recorded using an electronic weighing scale.

\subsection{Chlorophyll Content}

SPAD 502 chlorophyll meter (Spectrum Tech Inc; Aurora, IL; USA) was used to measure the total chlorophyll content in the leaves. Three readings were taken at three spots on a leaf of each plant and the average readings were recorded.

\subsection{Leaf Gas Exchange Measurement}

A LI-6400XT (Li-COR Inc; Nebraska; USA) portable photosynthesis system is used to measure the leaf gas exchange. The instrument was warmed and calibrated with the ZERO IRGA mode for 30 minutes. The measurements use optimal conditions set at $400 \mu \mathrm{mol} \mathrm{mol}{ }^{-1} \mathrm{CO}_{2}$, $30^{\circ} \mathrm{C}$ cuvette temperature, $60 \%$ relative humidity with air flow rate set at $500 \mathrm{~cm}^{3} \mathrm{~min}^{-1}$ and modified cuvette condition of $800 \mu \mathrm{molm}^{-2} \mathrm{~s}^{-1}$ photosynthetically photon flux density (PPFD). The measurement of gas exchange was carried out between 9.00 am to 11.00 am by using fully expanded young leaves that simultaneously measured net photosynthesis $(A)$, stomata conductance $\left(g_{s}\right)$ and transpiration rate $(E)$. Water use efficiency (WUE) was calculated by dividing net photosynthesis with transpiration rate. The operation is automatic and the data were stored in the LI-6400XT console and analyzed with the Photosyn Assistant Software (Dundee Scientific, Dundee, UK). Precautions have been taken to avoid errors during taking the measurements.

\subsection{Total Phenolics and Flavonoids Quantification}

The total phenolics and flavonoid measurement followed methods from [24]. Initially grounded plant tissue samples $(0.1 \mathrm{~g})$ was extracted with $80 \%$ ethanol $(10 \mathrm{~mL})$ on an orbital shaker for 120 minutes at $50^{\circ} \mathrm{C}$. The mixture then was filtered and the filtrate was used for the quantification of total phenolics and total flavonoids. Follin-Ciocalteu reagent (Sigma Aldrich, Missouri, USA; diluted 10-fold) was used to determine the total phenolic content of the leaf samples. The absorbance was measured at $725 \mathrm{~nm}$. The results were expressed as $\mathrm{mg}$ $\mathrm{g}^{-1}$ gallic acid equivalent (mg GAE g ${ }^{-1}$ dry sample). For total flavonoids determination, a sample $\left(1 \mathrm{~mL}\right.$ ) was mixed with $\mathrm{NaNO}_{3}$ (Sigma Aldrich, Missouri, USA; $0.3 \mathrm{~mL}$ ) in a test tube covered with aluminum foil, and left for $5 \mathrm{~min}$. Then $10 \% \quad \mathrm{AlCl}_{3} \quad$ (Wako Pure Chemical Industries Ltd; Tokyo, Japan; $0.3 \mathrm{~mL}$ ) was added followed by addition of $1 \mathrm{M} \mathrm{NaOH}$ (Kanto Chemical Co. Inc.; Hokkaido, Japan; $2 \mathrm{~mL}$ ). Later, the absorbance was measured at $510 \mathrm{~nm}$ using a spectrophotometer with rutin as a standard (results expressed as $\mathrm{mg} \mathrm{g}^{-1}$ rutin dry sample).

\subsection{Statistical Analysis}

Statistical Package for Social Sciences (SPSS) version 21 was used to analyze the data that have been recorded. A two-way ANOVA Test was conducted to analyze data for all the parameters in the experiment. Data are significant if the $p$-value level $\leq 0.05$.

\section{RESULTS AND DISCUSSION}

\subsection{Leaves Number}

Fig. 1 showed that the leaves number of Orthosiphon stamineus from 3 weeks after treatment (WAT) until the 12 WAT. There was significant difference between treatments observed in 9 WAT and 12 WAT $(p \leq 0.05)$. In week 9 , there was a significant difference between $1400 \mathrm{mg} \mathrm{L}^{-1}$ and $2100 \mathrm{mg} \mathrm{L}^{-1}$ which recorded 195.33 and 201.00 , respectively. In 12 WAT, there was a significant difference between $700 \mathrm{mg} \mathrm{L}^{-1}$ and $2100 \mathrm{mg} \mathrm{L}^{-1}$. The highest leaves number was found at the concentration of $700 \mathrm{mg} \mathrm{L}^{-1}$ that record 480 . At 
$700 \mathrm{mg} \mathrm{L}^{-1}$ the maximum leaves number was obtained in 0 . stamineus. This was followed by 0,1400 and $2100 \mathrm{mg} \mathrm{L}^{-1}$. The current result indicates that application of MWCNTs above $700 \mathrm{mg} \mathrm{L}^{-1}$ reduces the leaf production in $O$. stamineus. However, contradicting results were observed by Khodakovskaya et al. [13], that showed MWCNTs-treated tomato plants produce the same number of leaves compared to tomato plants that were grown in untreated soil.

\subsection{Total Plant Biomass}

The trends for the influence of MWCNT on total biomass from 0 to 12 WAT are shown in Fig. 2. It was observed that MWCNT has significantly influenced the total biomass of $O$. stamineus from 6 WAT to 12 WAT. Generally, as MWCNT was increased from $0>2100 \mathrm{mg} \mathrm{L}^{-1}$ the total biomass of $O$. stamineus was drastically reduced. At 12 WAT the highest total biomass was obtained in $0 \mathrm{mg} \mathrm{L}^{-1}(31.18 \mathrm{~g})$ followed by $700 \mathrm{mg} \mathrm{L}^{-1}(28.08 \mathrm{~g}), 1400 \mathrm{mg} \mathrm{L}^{-1}(27.91 \mathrm{~g})$ and lowest in $2100 \mathrm{mg} \mathrm{L}^{-1}$ that just recorded $24.80 \mathrm{~g}$. The reduction in total biomass suggests that addition of MWCNT induced toxicity effects to the plants. Toxicity effects usually reduced the growth of plants and this usually followed by a reduction in plant growth and this was manifested by a reduction in plant total biomass that was observed in the present study. The present result was an agreement with the study of [25] that observed Zucchini that exposed to MWCNT have reduced their total biomass upon exposure to MWCNT. The results contradicted with the findings of Tan and Fugetsu [26] that showed the MWCNTs increased Oryza sativa biomass from 71-90 \% under treatment with MWCNT. The current result showed that plant response to MWCNT was different with different plant species.

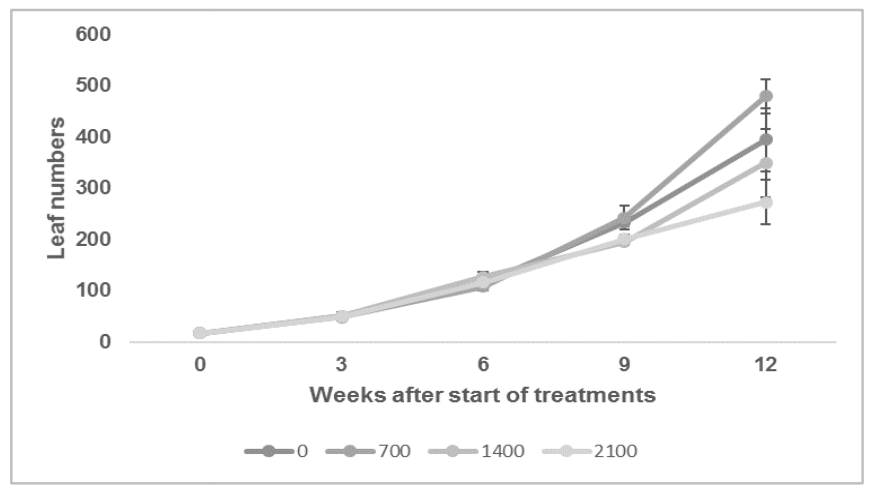

Fig. 1. Impact of multi-walled carbon nanotubes application on the leaf number of Orthosiphon stamineus during 12 weeks of planting

Data are mean \pm standard error of mean $(S E M) . N=9$. Means with * were significantly different at $p \leq 0.05$

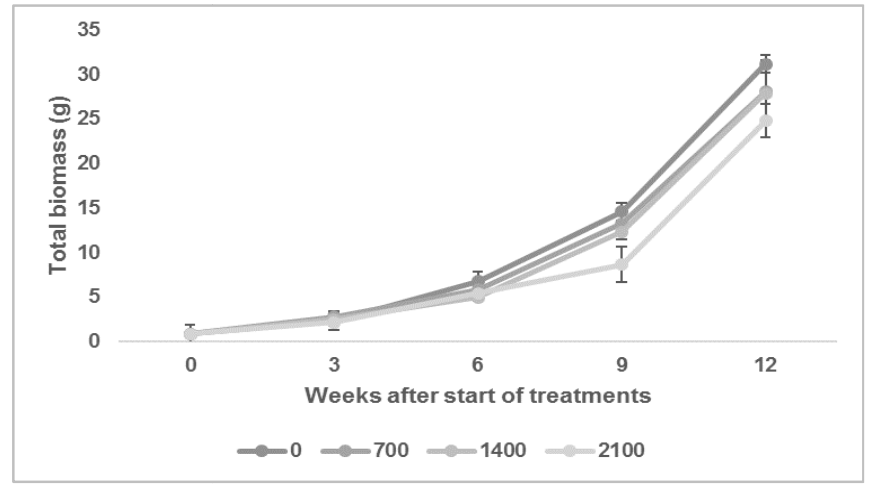

Fig. 2. Impact of multi-walled carbon nanotubes application on total biomass of Orthosiphon stamineus during 12 weeks of planting

Data are mean \pm standard error of mean $(S E M)$. $N=9$. Means with * were significantly different at $p \leq 0.05$ 


\subsection{Total Chlorophyll Content}

Fig. 3 shows the total chlorophyll content (TCC) of O.stamineus as affected by MWCNT application. In all weeks measured MWCNT has significantly influenced the TCC of $O$. stamineus. Generally, in all weeks measured, TCC was highest under $0 \mathrm{mg} \mathrm{L}^{-1}$ treatments followed by $700 \mathrm{mg} \mathrm{L}^{-1}, 1400 \mathrm{mg} \mathrm{L}^{-1}$, and $2100 \mathrm{mg} \mathrm{L}^{-1}$. The current result indicates chlorophyll reduction with the addition of MWCNT application to 0 . stamineus. This also indicates that the sink strength of this plant might be reduced under MWCNT exposure. Total chlorophyll content usually indicates the nitrogen status of the plant and the sink strength of plants [11]. The present study was in agreement with the study of Lin et al. [13] in Arabidopsis sp that showed decreased TCC upon exposure to MWCNT. In their study, the decreasing TCC was followed with the reduction in superoxide dismutase (SOD) activity and plant total dry weight. It can be concluded that MWCNT showed decreased growth patterns in $O$. stamineus that been justified with a reduction in TCC, that was observed in every week of the measurement in the present study.

\subsection{Leaf Gas Exchange Properties}

\subsubsection{Net photosynthesis}

The net photosynthesis rate of Orthosiphon stamineus was significantly influenced by the treatments of carbon nanotubes ( $p \leq 0.05$; Fig. 4 ). The net photosynthesis rate was decreased as the MWCNTs concentration increased from 0 $>2100 \mathrm{mg} \mathrm{L}^{-1}$. The highest $A$ was found to be in $0 \mathrm{mg} \mathrm{L}^{-1}$ concentration followed by $700 \mathrm{mg} \mathrm{L}^{-1}$, $1400 \mathrm{mg} \mathrm{L}^{-1}$ and lowest in $2100 \mathrm{mg} \mathrm{L}^{-1}$. Net photosynthesis is a term that measured the uptake of $\mathrm{CO}_{2}$ in the light [27]. The current result showed that application of MWCNTs has reduced the net photosynthesis of $O$. stamineus. This indicates that feedback inhibition occurs in O. staminues upon exposure to MWCNT. The reduction in $A$ under the accumulation of multiwalled carbon nanotubes might be due to stomatal obstruction imposed by MWCNT that induced heat production on leaves that simultaneously reduce the $A$. However, contradicting results were showed by [15], where the accumulation of CNTs in Arabidopsis sp has increased the rate of photosynthesis three times higher than that of controls and intensified maximum electron transport rates. Another study conducted by Giraldo et al. [16] indicated that upregulation in $A$ in spinach was due to ability of MWCNTs to penetrate the chloroplasts, and increased the electrons flow and simultaneously enhance the photosynthetic activity of the spinach.

\subsubsection{Transpiration rate}

The transpiration rate was significantly influenced by the MWCNTs concentration ( $p \leq 0.05$; Fig. 4). The same trend was observed for the transpiration rate where $0 \mathrm{mg} \mathrm{L}^{-1}$ recorded the highest transpiration rate $\left(2.69 \mathrm{mmol} \mathrm{m}^{-2} \mathrm{~s}^{-1}\right)$, followed by $700\left(1.67 \mathrm{mmol} \mathrm{m}^{-2} \mathrm{~s}^{-1}\right), 1400(1.31$ $\left.\mathrm{mmol} \mathrm{m}^{-2} \mathrm{~s}^{-1}\right)$ and $2100 \mathrm{mg} \mathrm{L}^{-1}\left(0.39 \mathrm{mmol} \mathrm{m}^{-2} \mathrm{~s}^{-1}\right)$. The transpiration rate decreased significantly as the concentration increased. This indicates that high concentration of MWCNTs inhibits the transpiration rate of the plants treated with MWCNTs. Transpiration is defined as the loss of water from the plant in the form of water vapor [28]. Transpiration only speeds up the rate and quantity of water moved and there is no evidence that the higher rates are beneficial [27]. In the

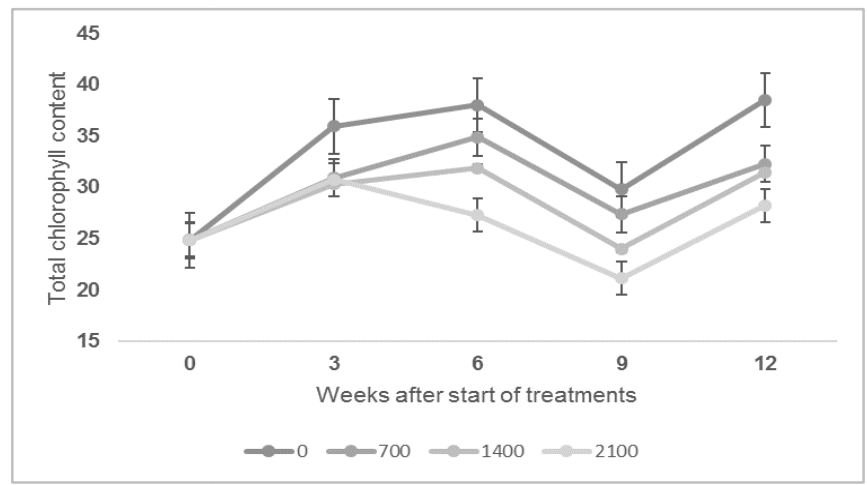

Fig. 3. Impact of multi-walled carbon nanotubes application on total chlorophyll content of Orthosiphon stamineus during 12 weeks

Data are mean \pm standard error of mean (SEM). $N=9$. Means with * were significantly different at $p \leq 0.05$ 


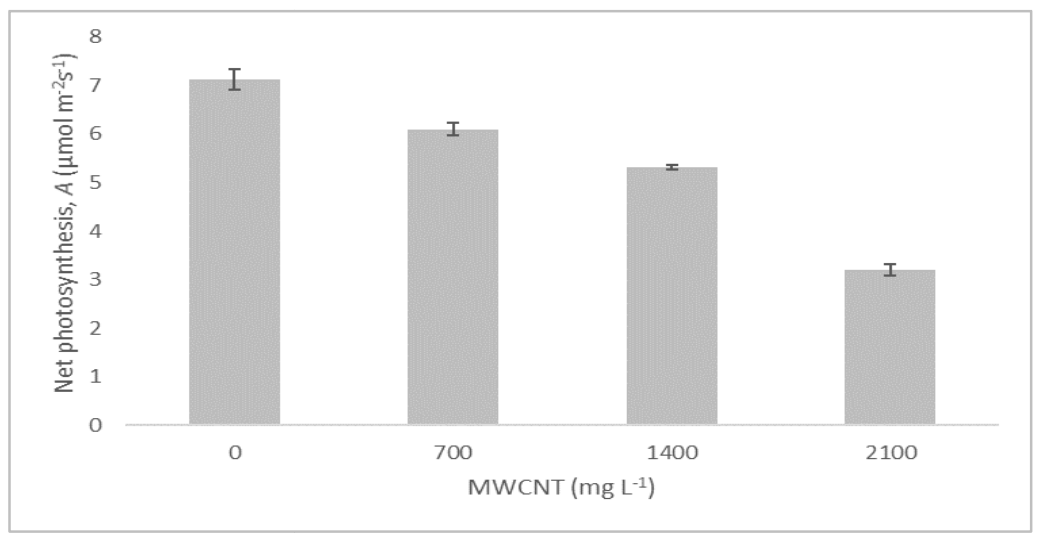

Fig. 4. Impact of multi-walled carbon nanotubes application on net photosynthesis of Orthosiphon stamineus during 12 weeks of planting. $\mathrm{N}=9$

Bars represent standard error of differences between means (SEM). Means not sharing a common letter were significantly different at $p \leq 0.05$

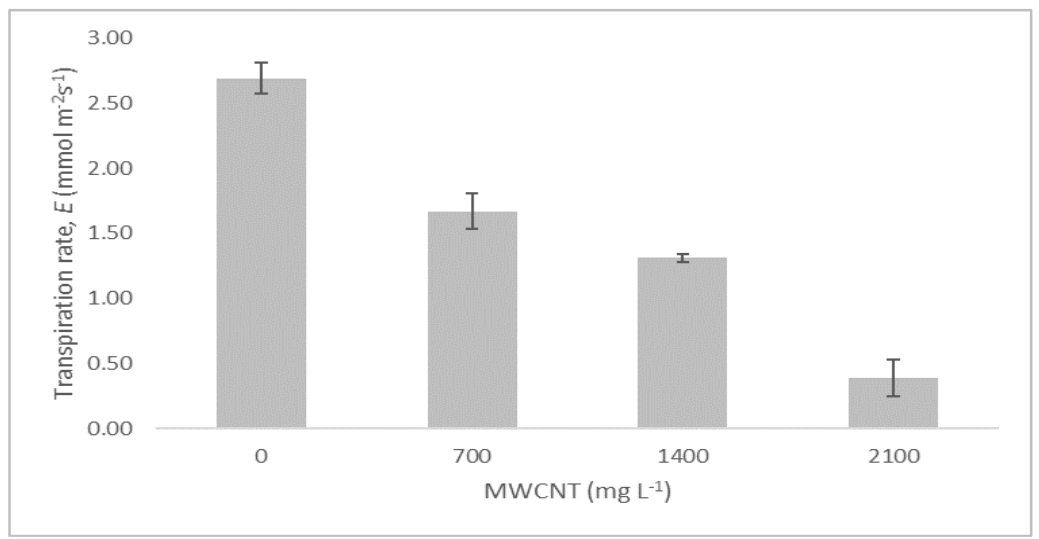

Fig. 5. The impact of multi-walled carbon nanotubes application on transpiration rate of Orthosiphon stamineus during 12 weeks of planting. $\mathbf{N}=9$

Bars represent standard error of differences between means (SEM). Means not sharing a common letter were significantly different at $p \leq 0.05$

current study, the reduction in $E$ of $O$. staminues might be induced by blockage of MWCNT on the surface of stomata of this plant. The reduction of E with the application of CNT was also observed by Voleti and Wait [29] on Arabidopsis thaliana seedlings where transpiration rate was $15 \%$ reduced with application of CNT on the plant. So it can be concluded that MWCNT has induced the reduction in transpiration rate in 0 . staminues in the present study.

\subsubsection{Stomatal conductance}

Stomatal conductance estimates the rate of gas exchange and transpiration rate as determined by the degree of stomatal aperture [30,31]. It is a function of the density, size and, degree of the stomata opening which allow greater conductance. High stomatal conductance indicates high transpiration and photosynthesis rate. This statement was proved by the results obtained in this study, where the declined of stomatal conductance decreased the net photosynthesis and transpiration rate of plants that were treated with high concentration of MWCNTs. Application of MWCNTs also influenced the stomatal conductance of Orthosiphon stamineus. There was significant difference shown between the four treatments ( $p$ $\leq 0.05$; Fig. 6). The highest stomatal conductance was found to be in $0 \mathrm{mg} \mathrm{L}^{-1}$ while lowest in $2100 \mathrm{mg} \mathrm{L}^{-1}$. The decrease in stomata conductance with the application of MWCNT might be due to increase in electrolyte leakage of 
the plant under MWCNT application that affects potassium pump mechanism of stomata opening. The increase in MWCNT might disrupt the accumulation of potassium that makes the stomata closed or partially closed under this condition $[11,16]$. It can be concluded that the reduction in stomata correspond to the decrease in photosynthesis $(A)$ and decrease in transpiration rate $(E)$ in the present study [30].

\subsubsection{Water use efficiency}

Application of MWCNTs have influenced the water use efficiency (WUE) of $O$. stamineus ( $p \leq$ 0.05 ; Fig. 7). The highest WUE of $9.74 \mathrm{umol} / \mathrm{CO}_{2}$ $/ \mathrm{mmol} / \mathrm{H}_{2} \mathrm{O}$ was obtained in $2100 \mathrm{mg} \mathrm{L}^{-1} \mathrm{MWCNT}$ treatments and the lowest WUE was recorded in $0 \mathrm{mg} \mathrm{L}^{-1}$ treatment that just recorded 2.66 umol $/ \mathrm{CO}_{2} / \mathrm{mmol} / \mathrm{H}_{2} \mathrm{O}$. There was no significant difference between $0 \mathrm{mg} \mathrm{L}-1$ and $700 \mathrm{mg} \mathrm{L}^{-1}$ MWCNT treatment in which WUE was recorded as 2.70 and 2.81, respectively. Water use efficiency is also referred as "transpiration efficiency". It is defined as the ratio of moles $\mathrm{CO}_{2}$ assimilated per moles of water transpired [26]. The increased of WUE is attributed to the increase of the transpiration rate and signifies the plant under water stress condition. This showed the exposure of the plant to MWCNT might induce water stress condition in the plant. The current result showed that the leaf gas exchange properties was decreased with application of MWCNTs.

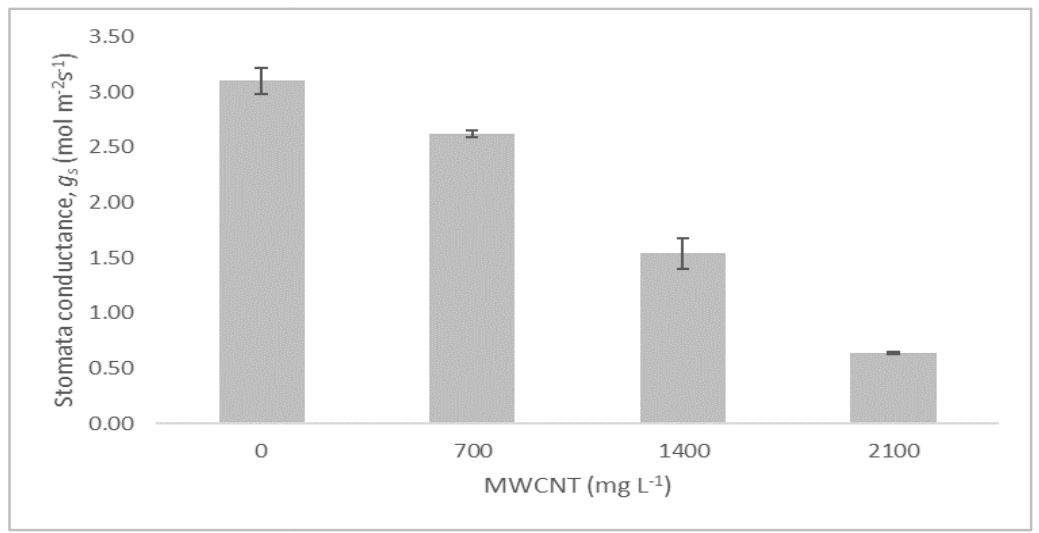

Fig. 6. Impact of multi-walled carbon nanotubes application on stomatal conductance of Orthosiphon stamineus during 12 weeks of planting. $\mathbf{N}=\mathbf{9}$

Bars represent standard error of differences between means (SEM). Means not sharing a common letter were significantly different at $p \leq 0.05$

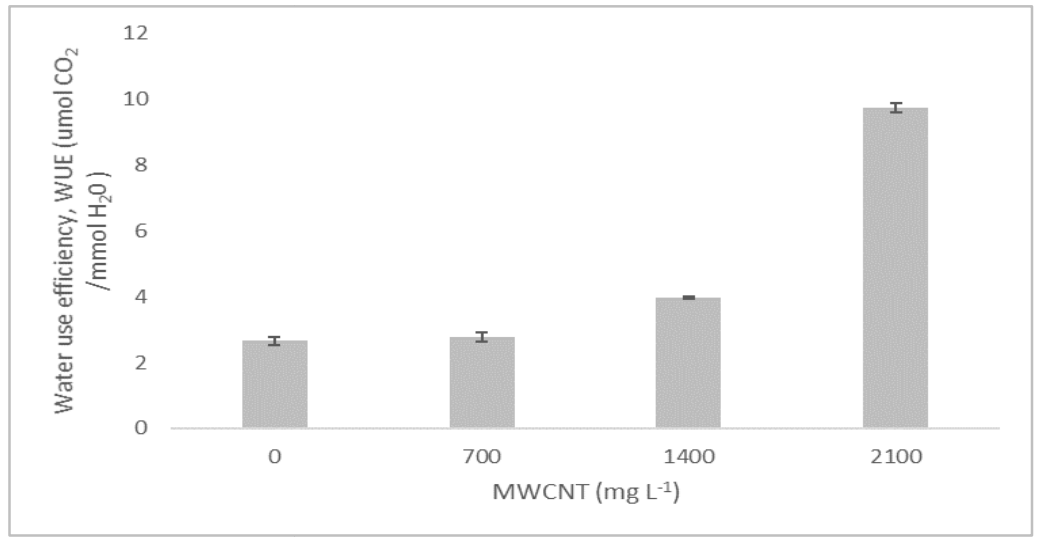

Fig. 7. The impact of multi-walled carbon nanotubes application on water use efficiency of Orthosiphon stamineus during 12 weeks of planting. $\mathbf{N}=9$

Bars represent standard error of differences between means (SEM). Means not sharing a common letter were significantly different at $p \leq 0.05$ 


\subsection{Effects of MWCNTs on Secondary Metabolites}

\subsubsection{Total phenolics}

In the current study, different MWCNTs concentration had a significant $(p \leq 0.05)$ impact on the production of total phenolics (Fig. 8). As the concentration of MWCNTs increased from 0 $\mathrm{mg} \mathrm{L}^{-1}$ to $2100 \mathrm{mg} \mathrm{L}^{-1}$, the 0 . stamineus plants produce more total phenolics. The plants being exposed to $0 \mathrm{mg} \mathrm{L}^{-1}$ registering the lowest value of total phenolics production $(0.20 \mathrm{mg} \mathrm{GAE} / \mathrm{g}$ dry weight) compared to $2100 \mathrm{mg} \mathrm{L}^{-1}$ concentration, which recorded $1.67 \mathrm{mg} \mathrm{GAE} / \mathrm{g}$ dry weight. The increased in plant secondary metabolites under high concentration of MWCNTs might be a response to the stress [31,32]. The plants being exposed to high concentration of MWCNTs produce high total phenolics to defend the plant system from any further damaged of the plant cells in order to survive. The high content of phenolic compounds contributes to the antioxidant activity [33]. Phenolic compounds are important for plants growth and reproduction which were produced as a response to environmental factors and to defend injured plants [21]. Lattanzio et al. [32] claimed that phenolic compounds have antibiotic, antinutritional or unpalatable properties that enable it to defend plants. Phenolics usually accumulated in the central vacuoles of guard cells and epidermal cells of leaves and shoots. The authors also proposed that plant phenolics may be divided into two classes which are preformed phenolics and induced phenolics. Preformed phenolics were synthesized during the normal development of plant tissues while induced phenolics were synthesized when the plants having any physical injury, infection and stressed by elicitors such as heavy metal-salts, UVirradiation, and temperature [33].

\subsubsection{Total flavonoids}

The total flavonoids were significantly influenced by the MWCNTs concentration ( $p \leq 0.05$; Fig. 9). The total flavonoids showed increasing trend as the MWCNTs increased. The plants that were exposed to $2100 \mathrm{mg} \mathrm{L}^{-1}$ record the highest value of total flavonoids production (1.27 mg rutin/g dry weight) while the lowest value of total flavonoids ( $0.17 \mathrm{mg}$ rutin/dry weight) was recorded by the plants exposed to $0 \mathrm{mg} \mathrm{L}^{-1}$. The current result indicates the production of total flavonoid was enhanced with elevated levels of MWCNT application. According to Moore [14], nanomaterials produce harmful reactive oxygen species (ROS), which elevates the cellular oxidative stress and may damage the DNA, proteins and membranes. ROS react nonspecifically with lipids, proteins and nucleic acids [25]. Thus, their increased generation can damage the cell structures, cell membranes and the photosynthetic apparatus [34]. The production of flavonoids may scavenge ROS within or near the sites of their generation [3537]. The majority of their functions result from their strong antioxidative properties [38-41]. The increase in flavonoid production with MWCNT was observed by [20] in Satureja khuzestanica where the application of MWCNT until $500 \mu \mathrm{g} / \mathrm{ml}$ have enhanced the production of total flavonoid, flavonoid, rosmarinic acid and caffeic acid in the

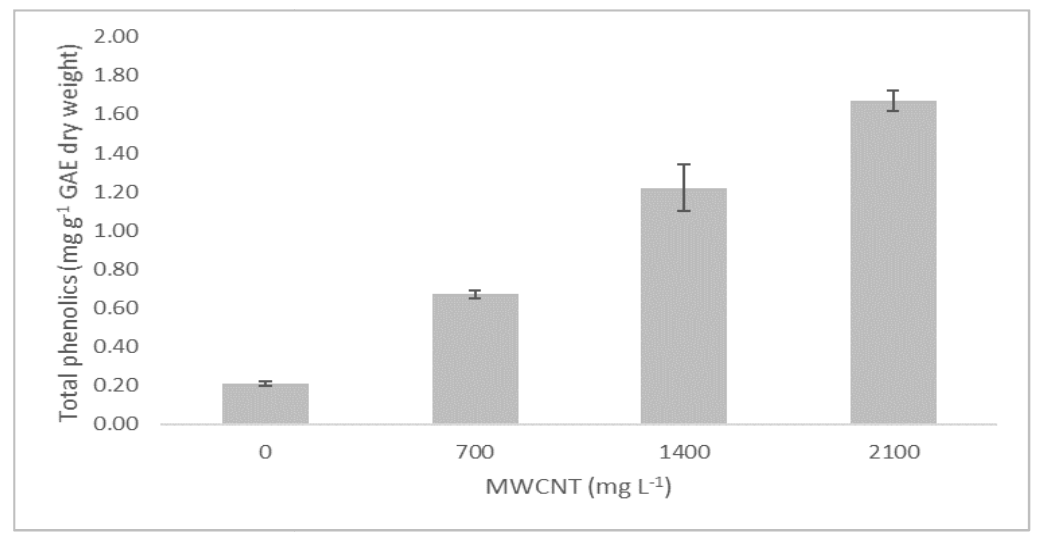

Fig. 8. Impact of multi-walled carbon nanotubes application on total phenolics of Orthosiphon stamineus during 12 weeks of planting. $\mathrm{N}=9$

Bars represent standard error of differences between means (SEM). Means not sharing a common letter were significantly different at $p \leq 0.05$ 


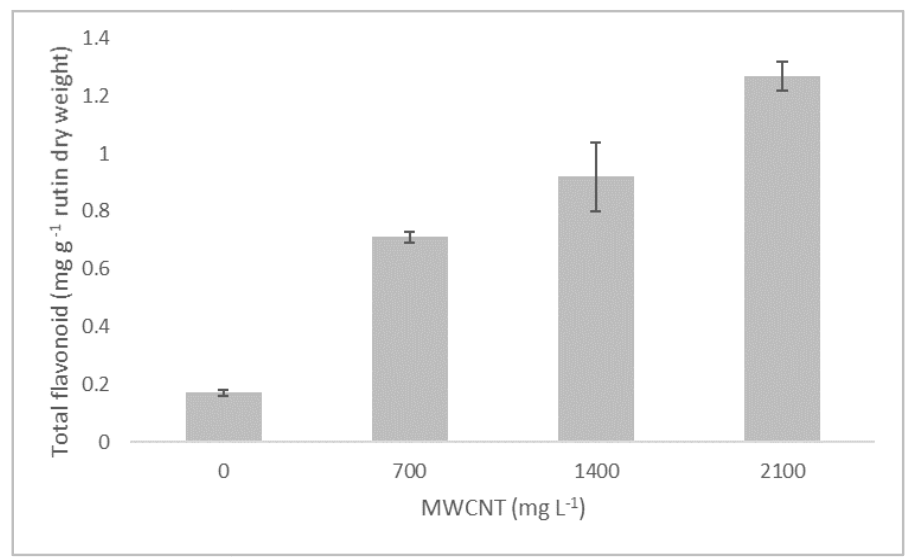

Fig. 9. Impact of multi-walled carbon nanotubes application on total flavonoids of Orthosiphon stamineus during 12 weeks of planting. $\mathrm{N}=9$

Bars represent standard error of differences between means (SEM). Means not sharing a common letter were significantly different at $p \leq 0.05$

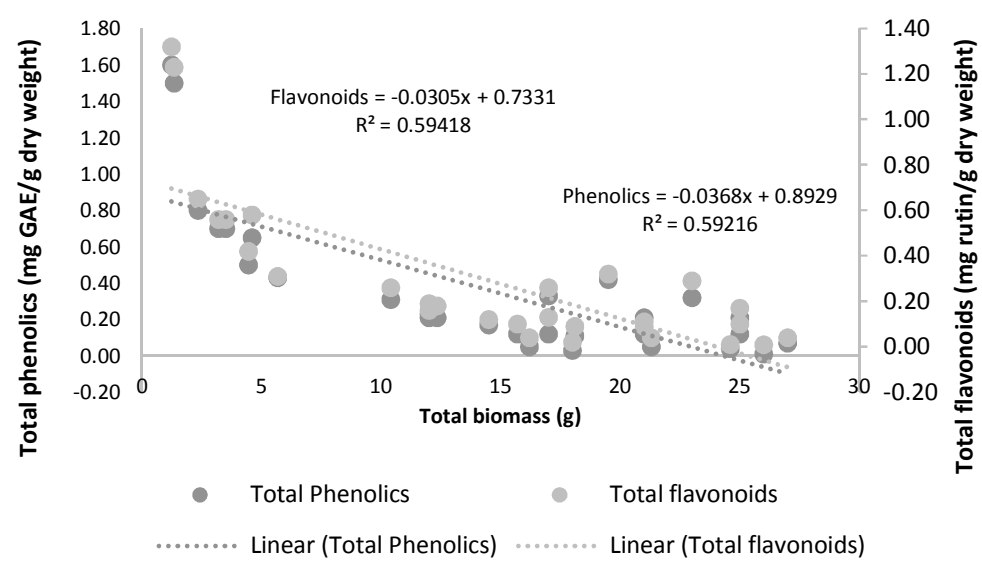

Fig. 10. The relationship between total biomass, total phenolics and total flavonoids of $O$. stamineus under MWCNT application

plant. So, it can be concluded that application of MWCNTs can affect the production of flavonoid content in O. stamineus. From Fig. 10 it was found that total biomass has a negative relationship with total phenolics $\left(R^{2}=0.592\right)$ and flavonoids $\left(R^{2}=0.594\right)$. This indicates that the production of plant secondary metabolites was inversely related to carbon assimilation of this plant $[42,43]$. Usually, plant would enhance the production of secondary metabolites and reduced production of biomass to acclimatized to abiotic and biotic stress [44-45]. So, it can be concluded in the present study application of MWCNT has induced plant stress and thus increase the production of total phenolics and flavonoids in the present study.

\section{CONCLUSION}

This work was devoted to assessing the impact of the application of MWCNT on the growth, leaf gas exchange and secondary metabolites production in $\mathrm{O}$. stamineus. The current result indicates that MWCNT that used in the study (23.6 - $28.1 \mathrm{~nm}$ in diameter) have influenced the growth, leaf gas exchange and secondary metabolites patterns of $O$. stamineus. It was found that addition of MWCNT to have reduced the growth and leaf gas exchange properties in this plant. From this investigation, it was shown that as growth and leaf gas exchange reduction as manifested with a reduction in total biomass, leaf numbers, net photosynthesis, stomatal conductance and transpiration rate as the rate 
increased from $0>700>1400>2100 \mathrm{mg} \mathrm{L}^{-1}$. The highest production of total phenolics and flavonoids was observed at $2100 \mathrm{mg} \mathrm{L}^{-1}$. This signifies that MWCNT induced plant stress response that enhanced the production of plant secondary metabolites in the present study. The reduction in plant biomass and increased in the production of secondary metabolites showed that $O$. stamineus acclimatized to abiotic factor that induced during the study. It is believed that the research objectives stated in the introduction have been met with the completion of this study.

\section{COMPETING INTERESTS}

Authors have declared that no competing interests exist.

\section{REFERENCES}

1. Ameer OZ, Salman IM, Asmawi MZ, Ibraheem ZO, Yam MF. Orthosiphon stamineus: Traditional uses, phytochemistry, pharmacology and toxicology. J. Med. Food. 2012;15(8):678.

2. Hsuan K. Order dan Famili Tumbuhan Berbiji di Tanah Melayu. Kuala Lumpur: Dewan Bahasa dan Pustaka; 1986.

3. Suddee S, Paton AJ, Parnell JAN. Taxonomic revision of tribe Ocimeae Dumort (Lamiaceae) in continental South East Asia III. Ociminae. Kew Bulletin. 2005;60:3-75.

4. Olah NK, Radu L, Mogosan C, Hanganu D, Gocan S. Phytochemical and pharmacological studies on Orthosiphon stamineus Benth. (Lamiaceae) hydroalcoholic extract. J. Pharma. Biomed. Analy. 2003;33:117-123.

5. Loon, YH, Wong JW, Yuen $\mathrm{KH}$. Determination of flavonoids from Orthosiphon stamineus in plasma using a simple HPLC method withbultraviolet detection. J. Chromato. B: Biomed. Sci. Appl. 2005;816(1):161-166.

6. Rico CM, Majumdar S, Duarte-Gardea S, Peralta-Videa JR, Gardea-Torresdey JL. Interaction of nanoparticles with edible plants and their possible implications in the food chain, J. Agri. Food Chem. 2011;59: 3485-3498.

7. Ma X, Geiser-Lee J, Deng Y, Kolmakov A. Interactions between engineered nanoparticles (ENPs) and plants: Phytotoxicity uptake and accumulation. Sci. Total Environ. 2010; 403:3053-3061.
8. Nair R, Varghese SH, Nair BG, Maekawa T, Yoshida Y, Kumar DS. Nanoparticulate material delivery to plants. Plant Sci. 2010; 179:154-163.

9. Lin D, Xing, B. Phytotoxicity of nanoparticles: Inhibition of seed germination and root growth. Environ. Poll. 2007;150:243-250.

10. Husen A, Siddiqi K. Carbon and fullerene nanomaterials in plant system. J. Nanobiotech. 2014;12(16):430-439.

11. De La Torre-Roche R, Hawthorne J, Deng $\mathrm{Y}$. Multiwalled carbon nanotubes and $\mathrm{C}_{60}$ fullerenes differentially impact the accumulation of weathered pesticides in four agricultural plants. Environ. Sci. Tech. 2013;47(21):12539-12547.

12. Parvin B, Brunshi F. Phytotoxicity of multiwalled carbon nanotubes on red spinach (Amaranthus tricolor L) and the role of ascorbic acid as an antioxidant. Hazard. Mat. J. 2014;243:212-212.

13. Khodakovskaya MV, Kim BS, Kim JN, Alimohammadi M, Mustafa T, Cernigla CE.Carbon nanotubes as plant growth regulators: Effects on tomato growth, reproductive system, and soil microbial community. Small. 2012;9(1):115-123.

14. Moore MN. Do nanoparticles present ecotoxicological risks for the health of the aquatic environment. Environ. Tech. 2006; 32:967-976.

15. Lin C, Fugetsu B, Su Y, Watari F. Studies on toxicity of multi walled carbon nanotubes on Arabidopsis T87 suspension cells. J. Hazard. Mat. 2009;170: 578-583.

16. Giraldo JP, Landry MP, Faltermeier SM, McNicholas TP, Iverson NM, Boghossian AA. Plant nanobionics approach to augment photosynthesis and biochemical sensing. Natural Mat. 2014;13:400-8.

17. Liu Q, Chen B, Wang Q, Shi X, Xiao Z, Lin $J$, Fang $X$. Carbon nanotubes as molecular transporters for walled plant cells. Nano Lett. 2009;(9):1-10.

18. Tiwari DK, Dasgupta-Schubert N, Villasenor LM, Tripathi D, Villegas J. Interaction of carbon nanotubes with mineral nutrients for the promotion of growth of tomato seedlings. Nano Stud. 2013;7:87-96.

19. Ramakrishna A, Ravishankar GA. Influence of abiotic stress signals on secondary metabolites in plants. Plant Signall. Behav. 2010;6(11):1720-1731. 
20. Ghorbanpour M, Hadian J. Multi-walled carbon nanotubes stimulate callus induction, secondary metabolites biosynthesis and antioxidant capacity in medicinal plant Satureja khuzestanica grown in vitro. Carbon. 2015;94:749-759.

21. Subbiah $R$, Veerapandian M, Yun KS. Nanoparticles: Functionalization and multifunctional applications in biomedical sciences. Curr. Med. Chem. 2010;17: 4559-4577.

22. Miralles P, Church TL, Harris AT. Toxicity, uptake, and translocation of engineered nanomaterials in vascular plants. Environ. Sci. Technol. 2012;46: 9224-9239.

23. Seung CL, Ye Z, Cheol JL. Low temperature growth of $\mathrm{ZnO}$ nanowire array by a simple physical Vapor deposition method. Chem. Mater. 2003;15:32943299.

24. Ibrahim $\mathrm{MH}$, Jaafar HZE, Rahmat $\mathrm{A}$. Zaharah AR. The relationship between phenolics and flavonoid production with total non structural carbohydrate and photosynthetic rate in Labisia pumila Benth. under High $\mathrm{CO}_{2}$ and nitrogen fertilization. Molecules. 2011;16:162-74.

25. De La Torre-Roche R, Hawthorne J, Deng Y, Xing B, Cai W, Newman LA, Wang Q., Ma X, Hamdi $\mathrm{H}$, White JC. Multiwalled carbon nanotubes and $\mathrm{C} 60$ fullerenes differentially impact the accumulation of weathered pesticides in four agricultural plants. Environ. Sci. Tech. 2013;47(21): 12539-12547.

26. Tan X, Fugetsu B. Multi-walled carbon nanotubes interact with cultured rice cells: Evidence of a self-defense response. J. Biomed. Nanotech. 2007;3:285-288.

27. Hopkins WG, Huner NPA. Plant Physiology. 4th ed. United States of America: John Wiley \& Sons Publishing; 2008.

28. Eichert T, Goldbach HE. Equivalent pore radii of hydrophilic foliar uptake routes in stomatous and astomatous leaf surfaceFurther evidence for a stomatal pathway. Physiol. Plant. 2008;132:491-502.

29. Voleti R, Wait DA.Effect of carbon nanotubes on plant growth and gas exchange using Arabidopsis thaliana. Technical Proceedings of the 2014 NSTI Nanotechnology Conference and Expo, NSTI-Nanotech. 2014;3:94-96.

30. Eichert T, Kurtz A, Steiner U, Goldbach $\mathrm{HE}$. Size exclusion limits and lateral heterogeneity of the stomatal foliar uptake pathway for aqueous solutes and watersuspended nanoparticles. Physiol. Plant. 2008;134:151-160.

31. Stanković MS. Total phenolic content, flavonoid concentration and antioxidant activity of marrubium peregrinum. Kragujevac J. Sci. 2010;33:63-72.

32. Lattanzio V, Lattanzio VMT, Cardinali A. Role of phenolics in the resistance mechanisms of plants against fungal pathogens and insects. Phytochemistry: Adv. in Res. 2006;23-67.

33. Kim D, Jeond S, Lee C. Antioxidant capacity of phenolic phytochemicals from various cultivars of plums. Food Chem. 2003;81:321-326.

34. Valentine IK, Maria VK, Bruno B. Phenolic cycle in plants and environment. Journal of Molecular Cell Biology. 2003;2:13-18. Kurepa J, Paunesku T, Vogt S, Arora H, Rabatic BM, Lu J, Wanzer MB, Woloschak GE, Smalle JA. Uptake and distribution of ultra-small anatase $\mathrm{TiO} 2$ alizarin red $S$ nanoconjugates in Arabidopsis thaliana. Nano Lett. 2010;10: 2296-2302.

35. Chinnamuthu CR, Boopathi PM. Nanotechnology and agroecosystem. Madras Agric J. 2009;96:17-31.

36. Kanazawa K, Hashimoto $\mathrm{T}$, Yoshida S, Sungwon P, Fukuda S. Short photoirradiation induces flavonoid synthesis and increases its production in postharvest vegetables. J. Agri. Food Chem. 2012;60:4359-4368.

37. Xie Y, Xu D, Cui W, Shen W. Mutation of Arabidopsis HY1 causes UV-C hypersensitivity by impairing carotenoid and flavonoid biosynthesis and the downregulation of antioxidant defence. J. Exp. Botany. 2012;63:3869-3883.

38. Ghasemzadeh A, Ghasemzadeh N. Flavonoids and phenolic acids: Role and biochemical activity in plants and human. J. Med Plant Res. 2011;5(31):6697-6703.

39. Dai J, Mumper R. Plant phenolics: Extraction, analysis and their antioxidant and anticancer properties. Molecules. 2010;15:7313-7352.

40. Apak R, Guclu K, Demirata B, Ozyurek M, Celik SE, Berker KI, Ozyurt D. Comparative evaluation of various total antioxidant capacity assays applied to phenolic compounds with CUPRAC assay. Molecules. 2007;12(7): 1496-1547. 
41. Peer WA, Murphy AS. Flavonoids and auxin transport:Modulators or regulators. Trends Plant Sci. 2007;12: 556-563.

42. Sugiyama A, Shitan N, Yazaki K. Involvement of a soybean ATP binding cassette-type transporter in the secretion of genistein, a signal flavonoid in legumeRhizobium symbiosis. Plant Physiol. 2007; 144:2000-2008.

43. Gould KS, McKelvie J, Markham K R. Do anthocyanins function as antioxidant in leaves. Plant, Cell \& Environ. 2002;25: 1261-1269.
44. Ibrahim $\mathrm{MH}$, Jaafar HZE. Primary, secondary metabolites, $\mathrm{H}_{2} \mathrm{O}_{2}$, Malondialdehyde and photosynthetic responses of Orthosiphon stimaneus Benth. to different irradiance levels. Molecules. 2012;17:1159-1176.

45. Ibrahim $\mathrm{MH}$, Jaafar HZE. Impact of elevated carbon dioxide on primary, secondary metabolites and antioxidant responses of Eleais guineensis Jacq. (Oil Palm) seedlings. Molecules. 2012;17: 5195-5211.

(c) 2018 Izad et al.; This is an Open Access article distributed under the terms of the Creative Commons Attribution License (http://creativecommons.org/licenses/by/4.0), which permits unrestricted use, distribution, and reproduction in any medium, provided the original work is properly cited.

Peer-review history:

The peer review history for this paper can be accessed here: http://www.sciencedomain.org/review-history/23109 